\title{
THE MOVEMENT OF THE SAME FOREPAW INDUCED BY STIMULATIONS OF TWO CONTRALATERAL CORTICAL REGIONS IN THE CAT
}

\author{
HIROSHI NAKAHAMA, SHIZUKO NATORI \\ AND HIROAKI KONO* \\ Laboratory of Neurophysiology, SEISHIN-IGAKU Institute, Itabashi-ku, Tokyo, Japan
}

Two separate cortical regions of the cat, posterior sigmoid gyrus and anterior ectosylvian gyrus, were reported by Adrian $(1,2)$ to receive impulses from the contralateral forepaw: the former area was named the first somatic sensory area; the latter, the second somatic sensory area. Since the anatomical and functional significances of these areas are not known, Woolsey $(10,11,12)$ suggested the terms somatic area I and somatic area II. And in somatic area II, face, arm and leg subdivisions were relatively well delineated (12).

Two specific problems will be dealt with here. First, an attempt has been made to determine whether there is any difference between somatic areas I and II to produce the movement of the contralateral forepaw of the cat by application of electrical stimulation; second, to determine whether these areas show the phenomenon of summation.

\section{MATERIAL AND METHODS}

Forty cats weighing $2.0-3.5 \mathrm{~kg}$. were used in this study. The animals were not anaesthetized. Exposure of the cortex of left side hemisphere by removal of bone was held to the minimum area essential for completion of the experiment. The exposed cerebral cortex was inundated with liquid paraffin at body temperature throughout the experiments. Under these conditions the cortex was well coloured, the arteries pulsated freely, and the brain did not bulge into, nor fall away from, the opening in the skull.

Square wave stimuli of $0.3-20 \mathrm{msec}$. duration and an amplitude of 1-36 volts were obtained from a generator triggered from the cathode-ray sweep and applied through an electrostatically shielded pulse transformer. Pulse duration, interval and voltage were independently variable.

Bipolar stimulation was used. Two thin silver wires ending in small knobs $(0.5 \mathrm{~mm}$. in each diameter) which were chlorinated electrolytically, were fastened together at from 0.8 to $1.2 \mathrm{~mm}$. distance and placed to the pia under direct observation hand-held. One or two minutes were allowed to elapse between successive stimulations. This time was considered long enough to allow after-effects from previous facilitations to be dispersed and to obviate "secondary facilitation"

Received for publication November 2, 1955.

* 中浜 博, 名取静子, 河野裕明 
$(3,8)$, since constancy of cortical response prevailed under these conditions. Positions of points stimulated were pointed out on a diagram which indicated the sulci and the vascular pattern. Often the points were also marked on the brain with india ink applied with the stimulating electrode, so they could be seen later in the fixed specimen.

The cortically induced movements were studied both by direct visual observation and with photographic records. Card board was pasted on a region which produced movement and the increase or decrease of light through it was measured with the use of photo cell with differential amplifier with a time constant of 4 sec. .

The animal was placed on a stand with its head supported by a metal bar held between the jaws, and the limbs fixed by strings to a rigid base. The elbow was semi-flexed and the forearm semi-pronated. The hindlimb was abducted at the hip with knee and ankle at right angles. All movements started from this initial posture.

Three observers watched the responses. Procedures for determining threshold voltage were as follows. Stimulation was first started at a very low voltage and increased by increments of 2-4 volts until the movement was detected. Thereafter, the voltage was lowered and one went above and below threshold on alternate trains gradually narrowing the range until one had the smallest detectable movement. The voltage was held at the threshold for the next few trains to see the responding part and the type and the timing of the movement clearly enough for agreement among the observers.

RESULTS

\section{Maps of cortical motor responses}

On stimulation of somatic area II in the cat, movements of the claws were produced by Adrian $(1,2)$. He drew attention to the fact that Ferrier (5) many years ago did the same. Garol (6) produced, by electrical stimulation, movements of face, arm and leg from somatic area II in the cat, although the localization pattern which he described does not agree with the pattern defined by evoked potentials. Woolsey (10) indicated that electrical stimulation of this area in the cat has produced movements localized to face, arm or leg depending on whether face, arm or leg subdivision was stimulated. Among these authors, there is noticeable discrepancy. To clarify this discrepancy, this experiment was made.

Figure 1 shows the results of single threshold stimulation to show the cortical maps. From somatic area II, a flexion limited only to the contralateral forepaw was produced. Among 12 cats examined in this experiment, 2 did not show clear anterior ectosylvian gyrus. Even in these cats, no particular different characteristics were shown from another 10 cats. One example of these two cats is illustrated in a lower left diagram of Figure $1 \mathrm{~A}$.

In this experiment, in order to determine the region of induced movement, the threshold value in one point of the cortex was determined. Thereafter the stimulated effects on the other points were determined by the same procedure. Accordingly, these points might have some after-effect of the stimulation on the 
$A$
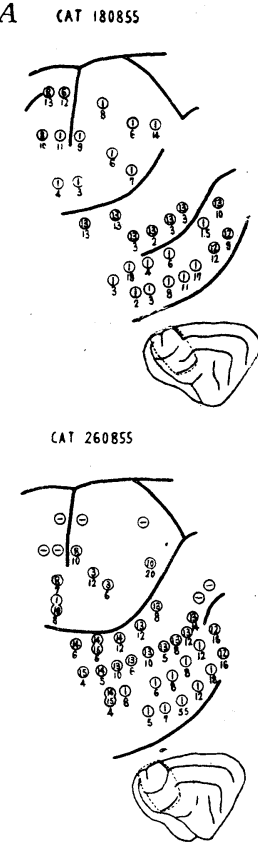

$B$

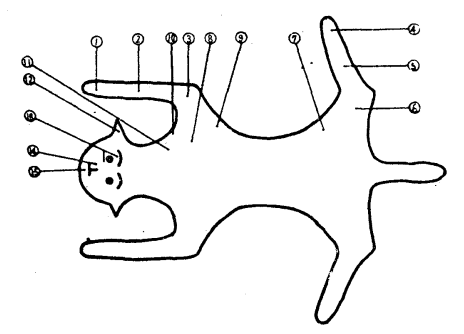

FIG. 1. Maps of cortical motor response (left hemisphere) in the cat ( 4 animals), summarizing the results of threshold stimulation with square wave pulse of $4.5 \mathrm{msec}$. duration.

In $(A)$ the stimulated points are indicated each with the mark $O$ and the number given in the mark represents the regions with induced movement and those regions are shown by numbers in $(B)$. The numbers given below $\bigcirc$ represent the threshold voltage required to give induced movements. $\theta$ indicates the negative induced movement by application of threshold voltage up to the maximum of 28 volts. previous point. However, such aftereffect was considered negligible, since stimulation was applied in one or two minutes interval $(3,8)$.

In somatic area II, the flexion limited to contralateral forepaw was produced even from face and neck regions, which Garol (6) described. Even with similar stimulus conditions as he used (threshold stimulation of 20 msec. pulses at 1 c.p.s. for $2 \mathrm{sec}$.), similar results mentioned above were obtianed from somatic II, although he used anesthetized cats. In a few cases, however, the movement limited to contralateral eyelid or ear could be produced from any portion in somatic II. Only in a few cases, the movement limited to contralateral leg could be produced as Woolsey (10) pointed out, by stimulation on leg subdivision in somatic II. These movements, however, could not be produced constantly. On the other hand, the flexion of contralateral forepaw could be produced constantly. In view of the experiments described above, it can be suggested that, in somatic II, there are overlap of representation of contralateral face, leg and forepaw. There is little evidence, however, to support Garol and Woolsey's results $(6,10)$.

\section{Comparison between somatic areas $I$ and II}

(a) Threshold value of motor response. No remarkable difference was recognized in threshold voltage to produce the motor response between somatic areas I and II, although somatic II showed a slightly lower value (fig. 1 ).

(b) Influence of duration of single pulse upon thresholds of motor response. Figure 2 shows that variations of du-

ration of single pulse had a similar influence upon thresholds of movements produced by the stimulation of somatic areas I and II. The greatest decline of 
threshold values occurred consistently at pulse durations of $0.3-5 \mathrm{msec}$. After reaching the plateau, curves remained essentially unaltered by further changes of pulse duration.

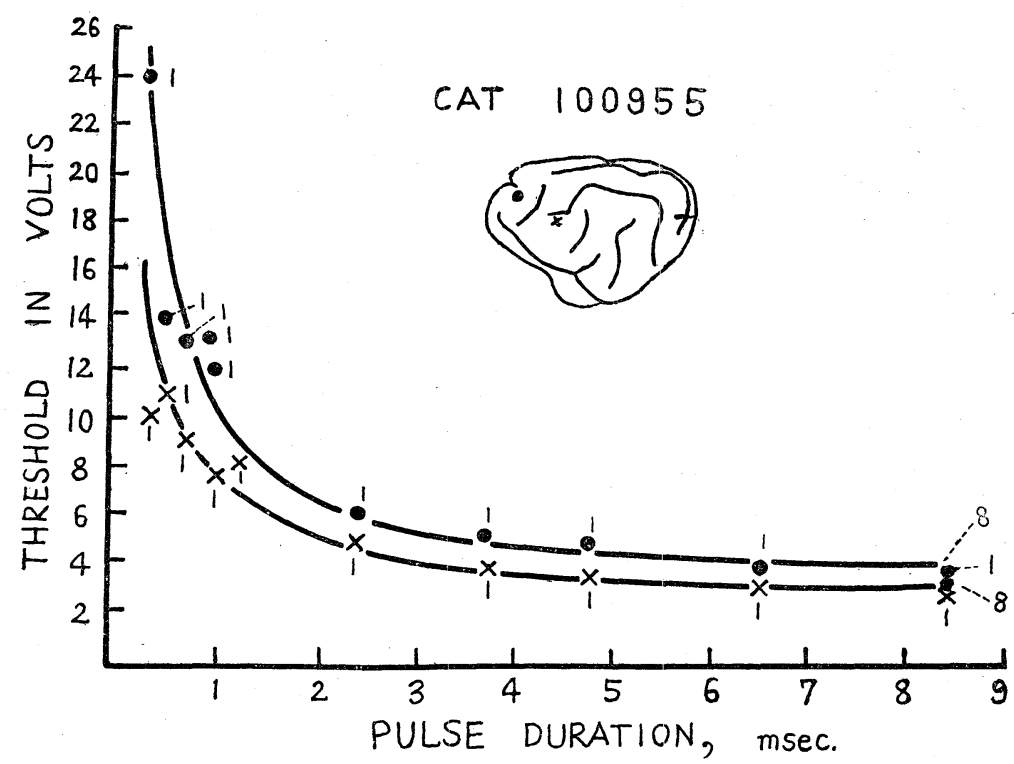

FIG. 2. Effect of varying duration of single pulse upon threshold of motor response.

- and $x$ denote the stimulated points and threshold voltage against pulse duration, in somatic areas I and II, respectively. The numbers shown around the mark indicate the region showing induced movement at the threshold voltage: those regions were shown in fig. $1 \mathrm{~B}$.

In somatic I, changing of the pulse duration often produced a change in the type of motor response, longer pulses favouring movements involving proximal muscle groups. This is in agreement with the results of Cure and Rasmussen (4) who used monkeys. In somatic II, different from their results, the movement limited only to muscle group in distal was produced regardless of pulse duration.

(c) Latency. In figure 3 the latency before the appearance of the flexion of the contralateral forepaw is shown at different strength of stimulation. The latency was shorter with stimulation of the greater voltage on somatic areas I and II. Accordingly, the shortest latency was sought as shown in table 1 . In somatic I, the latency was 16-22 msec.; in somatic II, 15-21 msec.. We thus arrive at the conclusion that no remarkable difference was recognized in latency between somatic I and II.

(d) Influence of varying interval between two pulses upon character of motor responses. Variations in pulse interval altered the quality of response produced by the application of 2 shots on the same point of somatic areas I and II, in which each shot was equal to the threshold value. An example of 


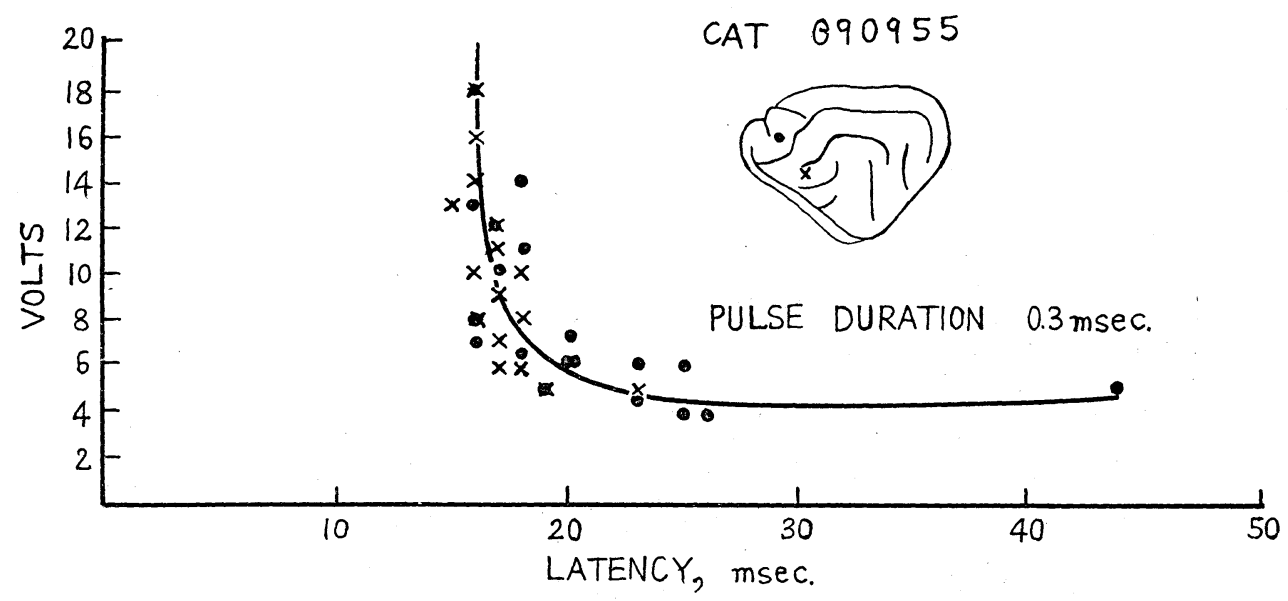

FIG. 3. Showing latency against strength of stimulation.

- and $x$ denote the stimulated region and the time required to produce the flexion of contralateral forepaw against various applied voltage, in somatic areas I and II, respectively. In somatic area $\mathrm{I}$, the region which produced a limited induced movement of contralateral forepaw was chosen at the threshold voltage. An increase in stimulus strength caused an entire movement of contralateral forelimb. Also in this case, the time required to give the flexion of forepaw was measured. Pulse duration was $0.3 \mathrm{msec}$.

TABLE 1. The Shortest Latency Before the Appearance of Flexion of Contralateral Forepaw

\begin{tabular}{c|c|c|c|c}
\hline & \multicolumn{2}{|c|}{$1 \mathrm{M}$} & \multicolumn{2}{c}{$2 \mathrm{M}$} \\
\cline { 2 - 5 } Cat $\downarrow \begin{array}{c}\text { Pulse } \\
\text { dura. }\end{array}$ & $0.5 \mathrm{msec}$ & $4.5 \mathrm{msec}$. & $0.5 \mathrm{msec}$. & $4.5 \mathrm{msec}$. \\
\hline 300855 & 16 & 17 & 16 & 18 \\
030955 & 18 & 19 & 18 & 19 \\
140955 & 19 & 19 & 18 & 21 \\
170955 & 20 & 20 & 15 & 16 \\
190955 & 21 & 22 & 20 & 20 \\
& $16 \sim 21$ & $17 \sim 22$ & $15 \sim 20$ & $16 \sim 21$ \\
\hline
\end{tabular}

This latency was determined from a curve to which spots were plotted with the use of the same method as in fig. 3 . Five cats were used with the use of stimulus duration of 0.5 and $4.5 \mathrm{msec}$. The points of applied stimulation were somatic areas $I(1 \mathrm{M})$ and II $(2 \mathrm{M})$.

the results is shown in figure 4 . In somatic I, with the use of $300-36$ msec., the second flexion of the contralateral forepaw was produced after its recovery from the first flexion; $35-26 \mathrm{msec}$, the second flexion without complete recovery from the first flexion; $25-10 \mathrm{msec}$., only one flexion with longer duration than that of application of single pulse. In somatic II, the same induced movement was produced when applied in order of 300-45 msec., 44-30 msec. and 29-10 msec. . In both cases, the stimulation of the second pulse produced larger flexion than the first, and its duration was longer. 


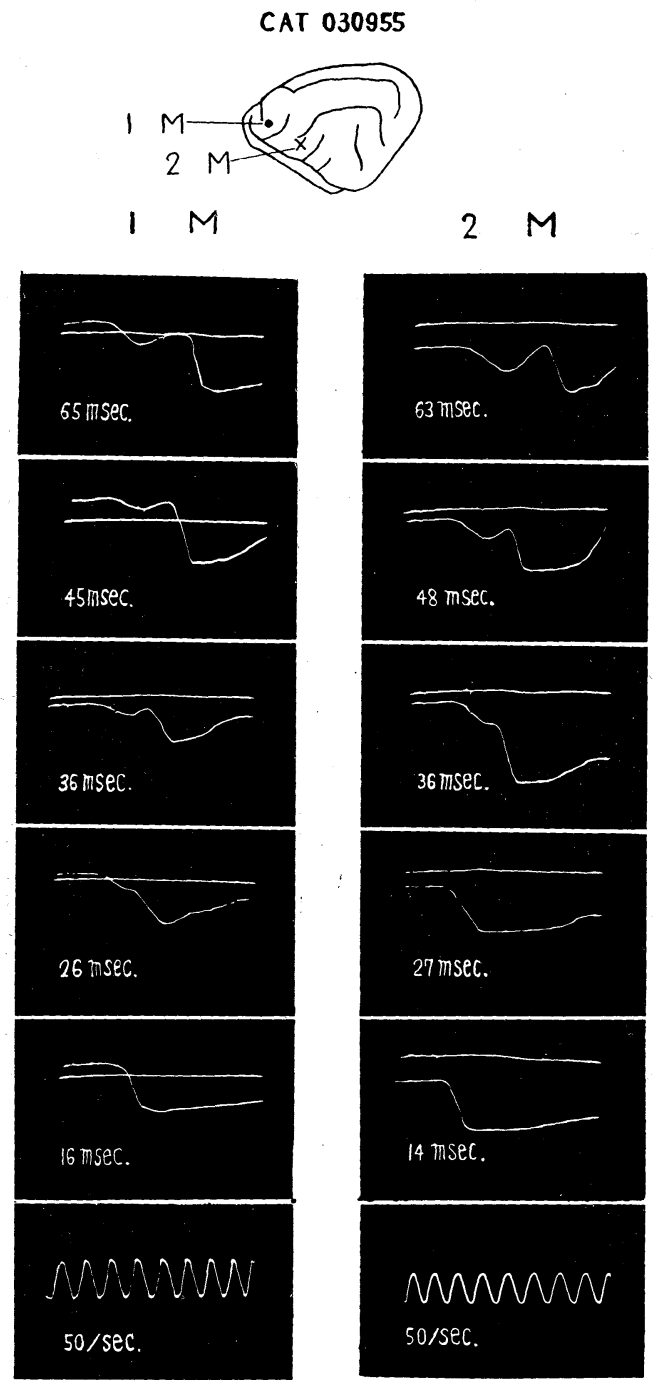

FIG. 4. The change of flexion of contralateral forepaw by application of 2 shots each on region $1 \mathrm{M}$ and $2 \mathrm{M}$. Pulse duration was $4.5 \mathrm{msec}$. The numbers given with msec. in each figure denote the pulse intervals.

Nearly straight lines in figure $1 \mathrm{M}$ and $2 \mathrm{M}$ represent the movement of shoulder and those of variable curves above or below the straight lines represent the flexion of the forepaw.

\section{The phenomenon of summation}

Figure 5 shows that the application of 2 shots on the same point of somatic areas I and II, in which each shot had equal subthreshold value, produced a flexion limited to contralateral forepaw. Figure 6 shows that almost simultaneous application of single pulse of subthreshold value on somatic areas I and II, respectively, produced a flexion limited to contralateral forepaw. We thus arrive at the conclusion that the phenomenon of summation was recognized on each or both somatic areas I and II. 


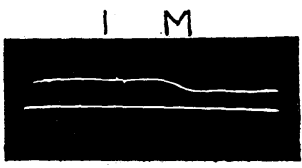

$2 M$
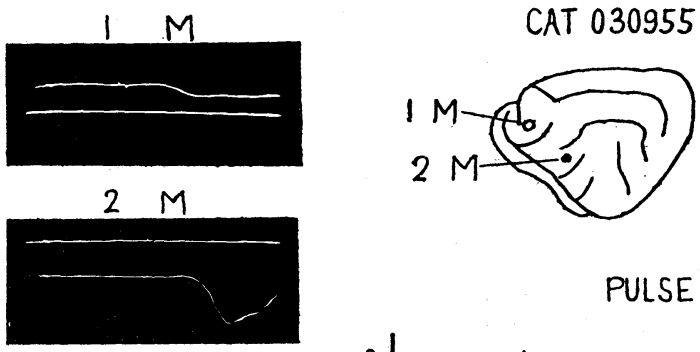

PULSE DURATION $4.5 \mathrm{msec}$.
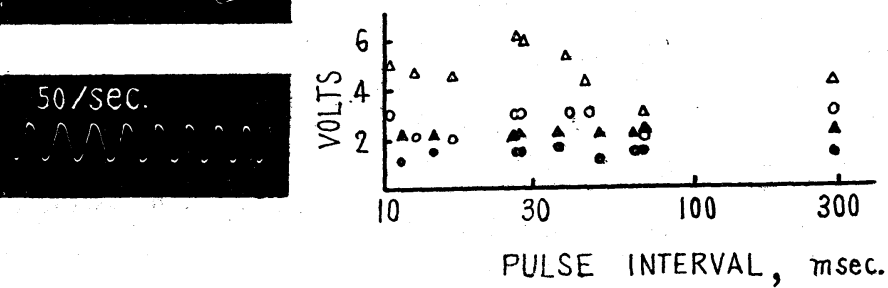

FIG. 5. The relation of stimulus threshold voltage and pulse interval by application of 2 shots respectively on somatic areas $I(1 \mathrm{M})$ and II $(2 \mathrm{M})$.

The left figure indicates the result of application of 2 pulses on $1 \mathrm{M}$ or $2 \mathrm{M}$, in which the first pulse was ineffective: the second pulse produced the flexion limited to contralateral forepaw. o and $\bullet$ denote the point of stimulation and threshold voltage which was effective in the second pulse. $\Delta$ and $\Delta$ denote the values of threshold voltage of the single pulse on each of $1 \mathrm{M}$ and $2 \mathrm{M}$ examined after 2 shots of subthreshold stimulation with various pulse intervals were applied. Pulse duration was $4.5 \mathrm{msec}$.

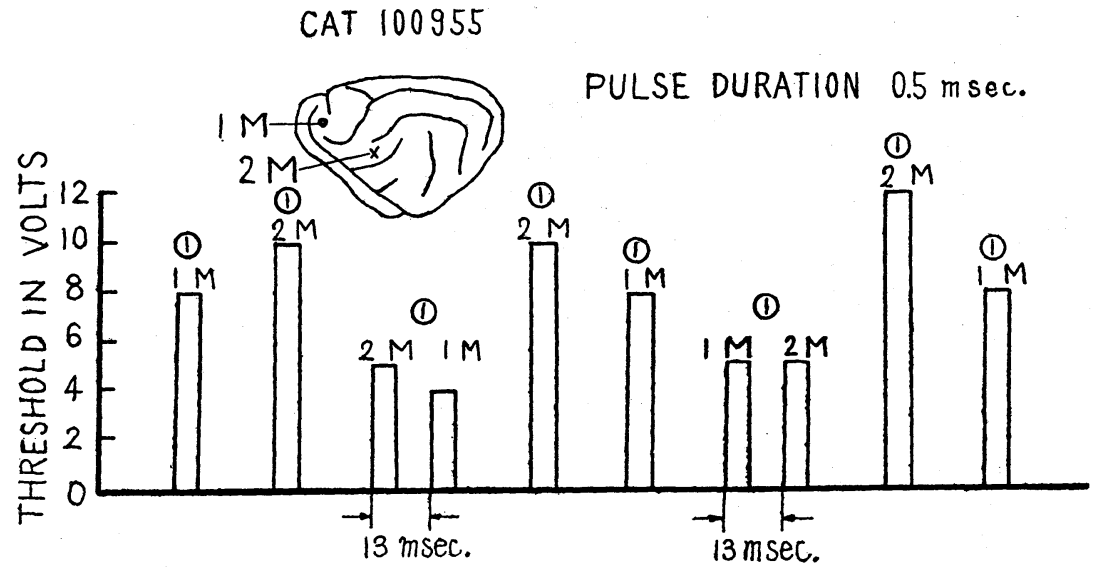

FIG. 6. Showing an induced flexion by applying 2 shots of single subthreshold pulse with $13 \mathrm{msec}$. intervals.

The numbers in $O$ indicate the regions of observed movement induced by threshold stimulation. Below the mark $\circ$, the stimulated points are indicated. The occasions of successive subthreshold stimulation on $1 \mathrm{M}$ and $2 \mathrm{M}$ are indicated with mark $\rightarrow|| \leftarrow$. 
DISCUSSION

Although it is possible to detect electrical changes around the position of electrode by means of recording of myogram, it is difficult to understand the total contraction or relaxation of a certain muscle from use of myogram alone. Moreover, it is impossible to make easier explanation of the movement caused by the resultant forces produced by the contraction or relaxation of various muscles. For explanation of the movement by myogram, it seems possible only after making a correct recording of the movement at first, then, inserting at least two electrodes in the same or different muscles at random; recording the movement and myogram at the same time to investigate the relation between the movement and the myogram. Also, the same is considered to be true for the method of recording action potentials from nerves as in the case of using myogram. Therefore, efforts have been made by the authors to make correct recordings of the movements as much as possible as a first step in this experiment, by use of the direct observation and photo cell.

The results of the present study show that the temporal and spatial summation occurred from somatic areas I and II and a flexion limited to a contralateral forepaw followed. Hayashi (7) determined the conducting path for clonic limb convulsions originating from the cerebral cortex in dogs and apes, indicating that neuronal relay runs to thalamus, lenticular nuclei, substantia nigra and anterior horn cell of spinal cord. It seems probable, therefore, that the site for summation processes from each and both somatic I and II are at subcortical and/or spinal levels. There is also no reason to exclude the possibility that somatic I and/or II is the site for summation processes, since these areas have been reported to be interrelated at the cortical level $(9,10)$. However, the investigation to determine the site for summation processes must be the subject of future research.

\section{SUMMARY}

Experiments were made on somatic areas I and II of the unanesthetized cat to produce the flexion of contralateral forepaw by electrical stimulation. In somatic II, there was little evidence to support Garol and Woolsey's results (6, $10)$, since the flexion limited to contralateral forepaw could be produced from any point in this area. Between somatic I and II, no remarkable difference was recognized in threshold value of motor response; influence of duration of single pulse upon threshold of motor response; latency before the appearance of motor response; influence of varying interval between two pulses upon character of motor responses. Moreover, the phenomenon of summation was recognized on each or both somatic I and II.

\section{ACKNOWLEDGMENT}

The authors wish to express their gratitude to Dr. M. Ueda for his constant interest, help and encouragement. They also desire to record their sincere thanks to Prof. T. Hayashi for his valuable advices, suggestions and criticisms made in the preparation of the paper. 


\section{REFERENCES}

1. ADRIAN, E. D. Double representation of the feet in the sensory cortex of the cat. J. Physiol. 98 : $16 \mathrm{P}-18 \mathrm{P}, 1940$.

2. ADRIAN, E. D. Afferent discharges to the cerebral cortex from peripheral sense organs. J. Physiol. $100: 159-191,1941$.

3. BRown, T. G. Studies in the physiology of the nervous system: XXIV. On the phenomenon of facilitation: 3. "Secondary facilitation" and its location in the cortical mechanism itself in monkeys. Quart. J. Exper. Physiol. 9 : 117-130, 1915-1916.

4. CuRE, C. and RASMuSSEN, T. Effects of altering the parameters of electrical stimulating currents upon motor responses from the precentral gyrus of Macaca Mulatta. Brain 77 : 18-33, 1954.

5. FERRIER, D. The functions of the brain. New York: G. P. Putnam's Sons, 1886.

6. Garol, H. W. The motor cortex of the cat. J. Neuropath. and Exper. Neurol. 1: 139145, 1942.

7. HAYASHI, T. A physiological study of epileptic seizures following cortical stimulation in animals and its application to human clinics. Jap. J. Physiol. 3: 47-64, 1952.

8. MCCulloch, W. S. Cortico-cortical connections, in Bucy, P. C.: The precentral motor cortex. Illinois Monographs in the Medical Sciences, Vol. 14, Chap. 8, 211-242 pp. Urbana, Ill. : University of Illinois Press, 1944.

9. SENCER, W. Interconnections of somatic afferent areas I and II of cerebral cortex of the cat. Am. J. Physiol. 163: 749, 1950.

10. Woolsey, C. N. Patterns of sensory representation in the cerebral cortex. Fed. Proc. $6: 437-441,1947$.

11. Woolsey, C. N. The somatic functions of the central nervous system. Ann. Rev. Physiol. 9: 525-552, 1947.

12. WoOlsey, C. N. and FAIRMAN, D. Contralateral, ipsilateral and bilateral represntation of cutaneous receptors in somatic areas I and II of the cerebral cortex of pig, sheep and other mammals. Surgery 19: 684-702, 1946. 